\title{
LA SOCIETALIZACIÓN DE LA PANDEMIA EN MÉXICO
}

\author{
SOCIETALIZATION OF THE \\ PANDEMIC IN MEXICO
}

\author{
Nelson Arteaga Botello \\ Flacso, México \\ nelson.arteaga@flacso.edu.mx
}

\begin{abstract}
It was analyzed how the management of the COVID-19 outbreak in Mexico was societalized. Societalization occurs when a problem considered as an institutional dysfunction is transformed into a social crisis that can end in sanctions or new institutional regulations. The societalization of the pandemic skyrocketed when the president claimed that he was immune to the virus due to his moral superiority and the protection of talismans. It is concluded that societalization was interrupted by political polarization in the country. Methodologically, the motivations, relationships, and institutions that were attributed to the president's statements in five national newspapers were examined.
\end{abstract}

Keywords: civil sphere, COVID-19, societalization, social problems, discursive disputes.

\section{Resumen}

Se analiza cómo se societalizó el primer esfuerzo del gobierno de México por controlar el brote de Covid-19. La societalización ocurrió cuando el presidente fue acusado de ser una amenaza la salud pública del país al asegurar que su superioridad moral lo hacía inmune al virus e impedía que fuera fuente de contagio. La polarización política del país evitó, como en otras ocasiones, que la societalización se tradujera en regulaciones o sanciones al presidente. Los argumentos contra el presidente se transformaron en un sedimento simbólico traído a cuenta por la esfera civil en otros esfuerzos por societalizar la pandemia.

Palabras clave: esfera civil, Covid-19, societalización, problemas sociales, competencia discursiva. 


\section{Introducción}

El artículo analiza cómo se societalizó el esfuerzo del gobierno de México por controlar el brote de Covid-19 en 2020. El proceso de societalización sucede cuando una disfunción institucional se convierte en una crisis social; esto es, cuando dicha disfunción pasa del control del mundo de las élites políticas, económicas o religiosas al ámbito de la esfera civil (Alexander, 2020; Lo y Hsieh, 2020). La societalización permite, algunas veces, la generación de regulaciones y sanciones a dichas élites, pero otras, no. El artículo muestra cómo en los días en que era inminente la dispersión de la Covid-19, el presidente Andrés Manuel López Obrador aseguró que contaba con una estrategia basada en criterios técnicos y científicos, aunque ciertas voces críticas lo acusaron de dilatar la puesta en marcha de dicha estrategia.

El proceso de societalización inició cuando López Obrador aseguró -respaldado por su subsecretario de Prevención y Promoción de la Salud, Hugo López-Gatell- que su superioridad moral y la protección que le brindaban ciertas imágenes religiosas lo hacían inmune al virus e impedían que contagiara a la población.' La esfera civil acusó, entonces, al presidente de moverse bajo principios irracionales. A decir de esta interpretación, el gobierno operaba como una amenaza a la salud pública. Tanto críticos como simpatizantes del presidente cuestionaron la gestión de la pandemia. Sin embargo, los simpatizantes del presidente terminaron finalmente por apoyarlo. Esto generó una polarización sobre el manejo de la pandemia que evitó que la societalización se cristalizara en regulaciones o sanciones al presidente. Así, se reconstituyó el debate previo a la societalización: las críticas volvieron a centrarse en la forma en cómo se gestionaba a la pandemia, aunque las críticas al

1 Jair Bolsonaro, presidente de Brasil, fue otro líder político latinoamericano que se negó a considerar la pandemia como un problema serio. Donald Trump, en los Estados Unidos, tampoco reconoció, en un principio, que el nuevo coronavirus era un peligro real para la salud pública de su país. presidente acabaron por transformarse en un sedimento simbólico que se ha traído a cuenta constantemente.

Este artículo es una aportación desde la esfera civil a los análisis sobre las políticas contra la Covid-19, en el que se enfatiza cómo los medios de comunicación disputan el sentido de las acciones estatales para controlar la pandemia (Demertzis y Eyerman, 2020; McCormick, 2020; Morgan, 2020; Villegas, 2020). ${ }^{2}$ Las investigaciones sobre la pandemia en México se han centrado en comprender la emergencia de dispositivos biopolíticos en la gestión de la población (Ortiz Arellano, 2020; Peña, 2020), el peso del populismo en la gestión de la pandemia (Rentería y Arellano-Gault, 2020) o los regímenes de poder/verdad en los discursos oficiales (Murillo, 2020). Estos enfoques se interesan en comprender cómo dispositivos, estilos y discursos del poder se imponen en la vida social, dejando en un segundo plano cómo se interpretan y cuestionan, desde la esfera civil, las intervenciones estatales. $^{3}$

El artículo abre con una discusión sobre los conceptos básicos de los procesos de societalización. Posteriormente, se pre-

2 Este artículo no analiza la capacidad de los Estados nación para gestionar una crisis sanitaria global, sino las interpretaciones de la sociedad a la acción del Estado frente a la Covid-19. Sobre la relación del sistema político y la gestión de la pandemia ver Cepaluni et al. (2020); sobre el desempeño diferencial de regímenes autoritarios y democráticos ver Alon et al. (2020) y Han (2020). Otros trabajos han reflexionado sobre los efectos positivos o negativos de la pandemia en las democracias occidentales (Žižek, 2020; Agamben, 2020; Latour, 2020; Taussig, 2020), pero son más especulaciones futuristas (Wieviorka, 2020) o teodiceas sociales (Arteaga y Cardona, 2020) que análisis sobre cómo los actores construyen mundos de sentido sobre la pandemia.

3 Los análisis en México sobre la pandemia se han centrado en examinar sus aristas religiosas (Gutiérrez y De la Torre, 2020; Agúndez Márquez, 2020), sexual-afectivas (Rodríguez Salazar y Rodríguez Morales, 2020), familiares (Ordoñez-Barba, 2020), delictivas (Balmori et al., 2020) o educativas (Báez y Ruíz, 2020). A escala global se ha analizado la construcción social del sentido de la pandemia en las redes sociales (Malhotra, 2020; Marchal y Au, 2020), en los medios de comunicación (Sonnevend, 2020), en las narrativas de enfermos, supervivientes y familiares de víctimas (Vicari y Murru, 2020; Milan y Treré, 2020; Abidin y Zeng, 2020), en las creencias religiosas (Alimardani y Elswah, 2020) y en la interacción en la vida cotidiana (Collins, 2020). 
senta el contexto social previo al brote del coronavirus, donde se destaca el escenario de polarización política del país. En el tercer apartado, se analiza cómo las primeras críticas al gobierno señalaron que actuaba de manera lenta contra el coronavirus. En un cuarto apartado, se examina cómo un conjunto de declaraciones del presidente y del subsecretario de Salud dispararon el proceso societalización. Se analizan, a continuación, los esfuerzos del campo estatal y sus simpatizantes por reaccionar y frenar la intervención de la esfera civil. En las conclusiones, se enfatiza el peso de la polarización política para traducir las exigencias de un mejor control de la pandemia y se resalta la relevancia del análisis de los procesos de societalización para explorar las dinámicas de significación social y política de la pandemia de Covid-19.

\section{El proceso de societalización}

La esfera civil se entiende como el espacio en el que la solidaridad cívica se negocia de manera constante, a través de la tensión interpretativa -cambiante y diferente- sobre el sentido de lo civil y lo incivil (Alexander, 2006; Lo y Hsieh, 2020); está organizada a través de discursos que expresan opiniones, marcan distancias, provocan desplazamientos y organizan lo que existe y lo que puede existir en la sociedad (Farge, 1994). Los discursos civiles buscan sacralizar o contaminar las acciones de personas o grupos que buscan producir o sostener cierto tipo de solidaridad (Jacobs, 1996; Smith, 2005), que se entiende como el sentimiento de estar conectado con los demás, que habilita a participar en la sociedad, respetando la individualidad y proporcionando la sensación de ser parte de una colectividad (Alexander, 2006: 13).

Los miembros de una sociedad tienen distintas interpretaciones sobre cómo cristalizar la solidaridad y expresan su desacuerdo sobre la forma en que se deben articular las demandas individuales y las obligaciones colectivas. La esfera civil es una arena de confrontación constante, donde sus ciuda- danos se imputan la cualidad de la pureza o impureza democrática o se tipifican como civiles o inciviles, estableciendo quién puede ser incluido en las membresías de solidaridad y ciudadanía. El carácter democrático civil/puro o incivil/impuro que se atribuyen los actores sociales es relacional: así como "no hay religión desarrollada que no divida el mundo entre salvados y condenados, no existe discurso civil que no conceptualice el mundo entre aquellos que merecen la inclusión y aquellos que no" (Alexander, 2006: 55).

Las imputaciones sobre las virtudes y el vicio cívico transcurren en tres niveles: motivos, relaciones e instituciones (Alexander, 2006). En el primero, se considera que un actor social está respaldado por motivos democráticos si se cree que es autónomo, racional, razonable y realista; por el contrario, se considera que es un actor inspirado por motivos antidemocráticos si se juzga que éstos carecen de autonomía, son irracionales y no realistas. En un segundo nivel, se evalúan las relaciones de los actores en términos civiles si se estima que son abiertas, confiables, susceptibles a la crítica, honorables y confiables; de otro modo, son calificadas como anticiviles si se evalúa que son cerradas, sospechosas, deferenciales, egoístas o tramposas. Finalmente, las instituciones se categorizan como civiles si se interpreta que están reguladas por la ley, son equitativas, inclusivas e impersonales; y se tipifican como anticiviles, si se evalúa que funcionan de manera arbitraria, jerárquica, excluyente y para beneficio de una persona o grupo.

La esfera civil provee una interpretación de las dinámicas estructurales de la inclusión y la exclusión de los discursos y de las instituciones democráticas (Kivisto y Sciortino, 2019). Mientras que el sentido de la disputa se construye de forma relacional (Alexander, 2006), la civilidad de unos se articula en el lenguaje de la incivilidad de los otros. Estas imputaciones se trasladan hacia las instituciones, a las que se acusa de ser o no democráticas e inclusivas. Las disputas sobre las atribuciones morales, civiles o inci- 
viles, se cristalizan de forma espacial y temporal en instituciones comunicativas y regulativas. Las primeras reflejan y difunden las posturas, pasiones e intereses de quienes se asumen como parte de una sociedad o forman una red de actores que hablan en nombre de la sociedad, hacia la sociedad y como sociedad (Kivisto y Scorttino, 2015). Entre estas instituciones están los medios de comunicación, las asociaciones voluntarias y los movimientos sociales. Las instituciones regulativas responden ante el reclamo social de solidaridad y poseen el derecho de tomar decisiones vinculantes, como sucede con los cargos electivos o tribunales.

Existen esferas no civiles que operan de forma distinta a la civil, a partir de sus propias lógicas de poder, estructuras, jerarquías y mundos morales, tales como el Estado, la economía o la religión (Alexander, 2006). El Estado es una organización burocrática impersonal, que ejerce control social a través de órdenes y principios de autoridad y fuerza. La esfera de la economía opera a partir de la productividad, el interés y la ganancia. La familia, por su parte, está ligada por lazos afectivos, pero depende de la potestad y la deferencia, no de la crítica. La religión, finalmente, genera lazos de comunicación y cohesión en función de una autoridad que media la relación entre los creyentes y Dios. Cada una de estas esferas establece relaciones de frontera con la esfera civil. A veces, los principios del Estado, el mercado, la religión o la familia son transferidos a la esfera civil por políticos, sacerdotes y padres de familia. También es posible encontrar dinámicas en sentido contrario: la solidaridad civil puede llegar a alterar la lógica económica, estatal, familiar y religiosa.

La societalización es el proceso a través del cual las esferas no civiles se perciben como amenazas a la sociedad como un todo, cuando se considera que funcionan como intrusiones que destruyen la solidaridad y las membresías de inclusión universal (Schmidt, 2020). Cuando los problemas específicos de las esferas no civiles se societalizan, significa que han sido colocadas bajo el escrutinio de las instituciones comunicati- vas o regulativas de la esfera civil. Se critica a sus élites, jerarquías y estructuras de poder. Se exige que sean transparentes y que se abran al escrutinio público (Park, 2019). Incluso, se pide que se apliquen las sanciones correspondientes si se han afectado el interés y la dignidad de las personas. Las crisis sociales son el resultado de las interpretaciones críticas que se hacen desde las instituciones de la esfera civil a las tensiones, lógicas y estructuras de las esferas no civiles (Binder, 2021). Esto significa que la societalización es un proceso de construcción de sentido, en la que participan agentes como los medios de comunicación, asociaciones civiles o movimientos sociales; estos agentes encuentran siempre resistencias de parte de quienes respaldan las solidaridades restringidas de las esferas no civiles.

El proceso de societalización puede ser entendido como un modelo secuencial de un Tiempo $1\left(T_{1}\right)$ a un Tiempo $5\left(T_{5}\right)$ en que ciertos agentes sociales presionan a las esferas no civiles a abrirse al escrutinio de sus principios de operación (Alexander, 2019). En términos analíticos, se puede imaginar que $\mathrm{T}_{1}$ es un hipotético "Estado estable", donde las relaciones de frontera entre la esfera civil y las esferas no civiles se caracterizan por las críticas de la primera a las segundas. Dichas críticas no cuestionan los principios de funcionamiento de las esferas no civiles y no demandan la irrupción de los principios y códigos civiles a su interior. En un $\mathrm{T}_{2}$, los códigos civiles se mueven hacia el interior de las esferas no civiles e interpretan el funcionamiento de estas últimas como una amenaza para la sociedad. Así, "lo que es normal es visto como patológico, como moralmente contaminado y socialmente disruptivo" (Alexander, 2019: 8), como algo que "está fuera de lugar" (Douglas, 1966), porque representa algo sucio y contaminado que debe ser purificado (Cottle, 2004). Esto puede producir intervenciones de las instituciones comunicativas y regulativas de la esfera civil en las esferas no civiles, en términos de regulaciones, sanciones o reparaciones a daños $\left(\mathrm{T}_{3}\right)$. En respuesta a las demandas de cambio y las trasformaciones instituciona- 
les, se generan reacciones para menoscabar las críticas de la esfera civil y restablecer la pureza de los principios de funcionamiento de las esferas no civiles $\left(T_{4}\right)$, lo que después de un tiempo genera un nuevo Estado estable $\left(T_{5}\right)$.

El modelo secuencial es un referente analítico, por lo que no todos los tiempos de $T_{1}$ a $T_{5}$ se materializan, ya que los principios y tensiones que operan al interior de las esferas no civiles pueden frenar o incluso revertir la societalización. Esto sucede en las sociedades marcadas por procesos de polarización: el reconocimiento de que existen ciertas amenazas a la solidaridad puede no ser suficiente para generar la societalización (Mast, 2019). Esta última resulta, a veces, inefectiva en las democracias polarizadas, porque las posiciones encontradas deciden movilizarse una contra otra en lugar de exigir la intervención en las instituciones no civiles (Alexander, 2018). La polarización impide la definición de una arena común de lucha, reduciendo la solidaridad, debilitando las instituciones de la esfera civil e intensificando la polarización social. Para que la societalización funcione deben existir audiencias ciudadanas que generen la sensación de que la sociedad comparte un estándar de evaluación civil, pese a la presencia de distintas ideologías e intereses políticos (Alexander, 2019).

Para el caso de México, cuando el gobierno trató de mostrar que era capaz de frenar la pandemia, las instituciones comunicativas de la esfera civil -particularmente la prensa y las redes sociales-cuestionaron la lentitud con la que el gobierno actuaba. Este momento transcurrió entre la última semana de febrero y el 15 de marzo de 2020, y puede ser considerado el hipotético "Estado estable" $\left(T_{1}\right)$. El día 16 de marzo, el subsecretario de Salud señaló, ante los cuestionamientos de que el presidente debía dejar de participar en reuniones, que López Obrador no era fuente de contagio del virus sino de la virtud moral. Dos días después, López Obrador afirmó que no podía contagiarse porque lo protegían talismanes y valores morales superiores. Esto se leyó como la prueba de que López Obrador y López-Gatell se comportaban irracionalmente, contaminando seriamente el funcionamiento de las instituciones de salud pública $\left(T_{2}\right)$. Este momento de societalización se extendió hasta el 23 de marzo. Sin embargo, no generó cambios en términos de regulaciones o sanciones a las autoridades $\left(T_{3}\right)$ Los simpatizantes del presidente menospreciaron las críticas al ejecutivo para restablecer los principios y la legitimidad de su actuar $\left(\mathrm{T}_{4}\right)$, generando así un nuevo Estado estable $\left(T_{5}\right)$.

El proceso de societalización se reconstruyó analizando las columnas políticas de cinco periódicos de circulación nacional (El Universal, Milenio, La Jornada, Reforma y Excélsior). ${ }^{4}$ Se reconoce que las columnas periodísticas son parciales y sesgadas en las interpretaciones que ofrecen, porque se construyen en marcos de interpretación anclados en referentes morales específicos (Earl et al., 2004: 67; McCarthy et al., 1996: 479). Este sesgo permite analizar cómo las interpretaciones de columnistas activan el proceso de societalización. Como sugieren Butler y Luengo (2016), los medios de comunicación construyen mensajes que traducen situaciones concretas en códigos civiles con pretensiones de universalidad, a través de valoraciones y narraciones. Se encontró un total de 941 columnas de opinión que trataron el tema de la Covid-19 entre el 1 de enero y el 31 de marzo de 2020. Destaca el hecho de que en los dos primeros meses de ese año, el número de columnas sobre el tema fue de 88 , mientras que en marzo fue

\footnotetext{
4 Es difícil establecer un perfil ideológico de los diarios en México, ya que en las páginas de cada uno hay columnistas que regularmente critican y apoyan al presidente, al tiempo que tienen posiciones ideológicas distintas. De forma general, se podría decir que Excélsior se encuentra a la derecha del espectro político mexicano, mientras que Milenio y El Universal en el centro y Reforma puede ser catalogado como liberal, en tanto que La Jornada está a la izquierda del espectro político; este último es el único diario que carece de diversidad ideológica en sus columnas políticas. Este artículo no busca mostrar cuántas notas positivas o negativas tienen el presidente y su subsecretario; cuantificaciones de este tipo soslayan las narrativas sobre las atribuciones que se imputan a los funcionarios, que es el objetivo central de este artículo.
} 
de 853. Esto permite observar cómo la pandemia adquirió de forma repentina un peso significativo en la opinión pública. ${ }^{5}$

En términos metodológicos, las columnas de opinión se leyeron distinguiendo las opiniones sobre qué tipo de motivos, relaciones e instituciones se imputaron a las declaraciones del presidente y su subsecretario de Salud. ${ }^{6}$ Las opiniones vertidas por los comentaristas se clasificaron en función de los juicios que hicieron sobre el carácter irracional o no de las declaraciones de López Obrador y López-Gatell; es decir, si se juzgaba que un problema de disfunción en la esfera estatal que ellos representan se percibía como amenazante a la sociedad como un todo. Siguiendo la metodología de la esfera civil, se estableció, en un primer momento, si en el sistema discursivo binario los motivos de ambos funcionarios eran considerados como civiles -esto es, racionales, justos, objetivos y realistas, además de si fueron juzgados como autónomos- o inciviles -es decir, irracionales, prejuiciosos, irrealistas o sujetos a manipulación-. En un segundo momento, se analizó si las columnas consideraron si el presidente y el subsecretario de Salud fomentaban relaciones

5 La referencia al número de notas que se incrementa de febrero a marzo es para mostrar el quiebre que presenta el tema de la Covid-19 de un mes a otro en la opinión pública. Agradezco a Danny Daniel Mollericona Alfaro su apoyo en la búsqueda, análisis y sistematización de la información periodística.

6 Esta metodología reconoce la autonomía relativa de la semántica cultural y no considera esta última como un epifenómeno del poder o de la dominación, como sugiere el análisis del discurso desarrollado por Foucault y Van Dijk. De igual forma, se toma distancia del análisis de contenido de Krippendorff, ya que su análisis de los textos carece de una teoría sociológica de alcance medio y sólo apunta a examinar cómo se definen los textos en función de su contenido simbólico. En este artículo se sigue una propuesta teórica de alcance medio (la societalización dentro de la teoría de la esfera civil), que establece un criterio metodológico específico que explora las atribuciones que en los textos se hacen a los supuestos motivos, relaciones e instituciones de representantes políticos, figuras públicas y civiles. Al enfatizar cómo las columnas asignan atribuciones sobre los motivos, relaciones e instituciones, se asume la autonomía relativa de la producción de sentido, así los significados no son superestructuras o ideologías dependientes de relaciones causales: las interpretaciones de los actores, y las estructuras culturales de las que ellas dependen, son el centro del análisis que aquí se propone. abiertas, críticas y francas -es decir, plenas de virtudes civiles- o cerradas y discrecionales, orientadas a satisfacer intereses específicos y acotados. En tercer lugar, se examinó qué tipo de instituciones perfilaban con su actuación: reguladas, bajo el imperio de la ley, equitativas e inclusivas o, por el contrario, arbitrarias, discrecionales, jerárquicas y excluyentes. A través de esta metodología se observaron los elementos de pureza e impureza civil atribuidos a ambos funcionarios. ${ }^{7}$

Al revisar las notas se observó la "relativa estabilidad empírica" del Estado estable $\left(T_{1}\right)$ que transcurre entre la tercera semana de febrero hasta mediados de marzo. En este mes, la esfera civil rompe el aislamiento discursivo de la pandemia a cargo del presidente y el subsecretario de Salud, mostrándolos como una amenaza. Las columnas se organizaron en tres concentraciones temáticas con el fin de comprender: a) la societalización de la pandemia $\left(T_{2}\right)$, b) las alteraciones en las instituciones frente al proceso de societalización $\left(T_{3}\right)$ y c) la reacción de la esfera estatal para restablecer sus principios de operación $\left(\mathrm{T}_{4}\right)$. El primer conjunto temático englobó las críticas y apoyos a las acciones de gobierno; el segundo, los cuestionamientos al liderazgo de López Obrador; el tercer conjunto se enfocó en la actuación de López-Gatell. ${ }^{8} \mathrm{Fi}$ nalmente, se agruparon las notas y columnas que mostraron la forma en cómo se restableció un nuevo Estado estable $\mathrm{T}_{5}{ }^{9}$

7 Otro tipo de análisis puede ser interpretar la disputa examinando cómo se expresó la gente en las cuentas oficiales de las columnas analizadas. Esto permitiría ver las reacciones de ciertos grupos de la sociedad frente a la opinión de los columnistas y establecer su peso en el proceso de societalización. A futuro, el proyecto más amplio en el que se inscribe este artículo permitirá profundizar en estos y otros temas.

8 Existen otras concentraciones que reflejan otras disputas, como la crisis económica, los escenarios futuros de la pandemia tanto a nivel nacional como internacional, así como las alteraciones en la vida cotidiana por el confinamiento.

9 Para este artículo se referenciaron 32 artículos, garantizando la presencia de columnistas de los cinco periódicos revisados y reflejando la pluralidad de posiciones. 


\section{El escenario previo a la pandemia}

López Obrador ganó las elecciones presidenciales por un amplio margen en 2018, luego de dos intentos fallidos en 2006 y 2012. En las tres campañas presidenciales, López Obrador desplegó un discurso populista, donde se presentó como la legítima e indiscutible encarnación del pueblo (Rentería y Arellano, 2020). El presidente ha insistido, desde su primer día de gobierno, en que la sociedad mexicana está polarizada. Por un lado, está el pueblo explotado y dominado; por el otro, un grupo opresor y corrupto, "la mafia del poder", que comprende partidos políticos, tecnócratas, empresarios, intelectuales, sociedad civil y medios de comunicación. Según López Obrador, para que el país avance a la democracia es necesario desmantelar las instituciones a las que pertenecen estos grupos de poder (Arteaga Botello, 2021). Su discurso ha generado posiciones en contra y a favor de su gobierno, dibujando un clima de polarización política. Pese a ello, al final del primer año de su gestión, entre $60 \%$ y $79 \%$ de los ciudadanos aprobaron su gobierno, destacando sus esfuerzos para acabar con la corrupción y reducir la pobreza (El Universal, 2019; Expansión Política, 2020a).

Con este respaldo a su favor, López Obrador anunció en los primeros días de 2020 una serie de acciones. Primero, garantizar la gratuidad de la salud en México (Gómez, 2020). Segundo, rifar el avión oficial del presidente..$^{10}$ Tercero, reformar el Instituto Nacional Electoral (INE), ya que, desde su punto de vista, operaba al servicio de conservadores y reaccionarios (Aguilar Camín, 2020a). Esta última propuesta fue cuestionada por funcionarios del INE, jueces, organizaciones de la sociedad civil, medios de comunicación y redes sociales, ya que se consideró que la intención del presidente era crear una institución a modo para controlar las elecciones. Sin embargo,

10 Una de sus propuestas de campaña fue que vendería un costoso avión presidencial que adquirió su antecesor. Ya como presidente, López Obrador intentó venderlo, pero no pudo; decidió rifarlo a través de boletos expedidos por la Lotería Nacional. una creciente ola de violencia y feminicidios en el país generó una amplia movilización feminista que opacó la agenda política del presidente. López Obrador afirmó que los feminicidios eran causados por "el modelo neoliberal" y advirtió que detrás de las feministas había conservadores que buscaban desestabilizar su gobierno (Nájar, 2020). El colectivo feminista "Brujas del mar" convocó entonces a un paro nacional de mujeres el 9 de marzo. El presidente respondió que había que "tener mucho cuidado" con las protestas feministas, ya que querían poner al pueblo en su contra. Acusó que esos movimientos se usan regularmente para cometer golpes de Estado, como sucedió en Chile en los años setenta (Jardínez Hernández, 2020). Esto desató, de nuevo, un proceso de polarización en la opinión pública a favor y en contra del presidente.

El temor de que la pandemia de Covid-19 llegara a México abrió otro frente al gobierno. El presidente anunció que el subsecretario López-Gatell daría todos los días una conferencia vespertina con el fin de informar sobre el comportamiento del virus (Garrido de Sierra, 2020). Aseguró que el país estaba en fase 1 de contagio; es decir, los casos reportados eran importados. El paro nacional de mujeres se llevó a cabo el 9 de marzo y fue considerado por los críticos del presidente como un éxito, mientras que quienes respaldaban la posición de este último acusaron que fue un fracaso (Cardona y Arteaga, 2020). Las posiciones encontradas con respecto al paro nacional mostraron, de nuevo, el grado de polarización en el país. Con todo, la disputa sobre la legitimidad del paro feminista fue desplazada poco a poco por otros temas: el desplome de los precios del petróleo, la devaluación del peso frente al dólar y la caída de la bolsa de valores (Ordaz, 2020).

\section{Estado estable: la operación tardía y errática}

El 14 de marzo, sólo cinco días después del paro nacional de mujeres, López-Gatell anunció la Jornada Nacional de Sana Dis- 
tancia, la cual habría de comenzar el 20 de marzo. Dicha jornada contemplaba la suspensión de las actividades no esenciales (eventos masivos, servicios en restaurantes, cines, plazas comerciales y actividades escolares). Se recomendó a la población mantener "sana distancia" -garantizar un espacio de un metro y medio entre las personas-, usar cubrebocas y lavarse constantemente las manos. El anuncio de las medidas desató una serie de críticas hacia López-Gatell, a quien se acusó de ser "pasivo e indolente" al impulsar las medidas contra la pandemia (Berrueto, 2020a; Marín, 2020a).

López Obrador fue imputado con las características de la impureza civil. Se dijo que su reacción frente a la pandemia respondía a su ignorancia, irracionalidad y emociones o, quizás, era parte de una estrategia para afianzar su poder político. Con respecto al primer tipo de imputaciones, se dijo desde Milenio que López Obrador carecía de los "reflejos políticos necesarios", que estaba "desinformado, sin sentido de empatía y en ocasiones molesto y, sobre todo, voluntarioso" ante la pandemia (Berrueto, 2020a). Desde el Reforma se le acusó de estar atrapado en "sus impulsos y apenas lograr fre$\mathrm{na}[r]$ sus arranques. [...] El presidente, lejos de ser ejemplo de buen juicio, da lecciones de una irresponsabilidad que raya en lo criminal" (Silva-Herzog, 2020). En este mismo tenor, una columna de Milenio advirtió que el presidente tomaba "decisiones oficiales que van de lo demencial a lo criminal" (Fernández de Cevallos, 2020).

Para algunos columnistas, el comportamiento irracional del presidente permitió que se perdiera tiempo valioso para enfrentar la pandemia. En una columna de Milenio se señaló que "el gobierno de México está en una fase de negación similar a la que tuvo Trump. Aplaza la respuesta seria al virus. Pierde preciosos, peligrosísimos, días" (Aguilar Camín, 2020b). Mientras que en el Excélsior, un columnista argumentó:

"hemos perdido dos o tres semanas muy valiosas para preparar al país para la llegada del coronavirus, no sólo en términos de salud pú- blica, sino también de blindaje económico y financiero. Hemos subestimado la amenaza y estamos reaccionando tardíamente a un fenómeno que puede tener consecuencias muy graves" (Fernández Menéndez, 2020).

Quienes consideraron que el comportamiento del presidente respondía a una estrategia política, advirtieron que ponía por delante su ambición personal a la salud de la población. Se afirmó, desde distintas columnas del Reforma, que López Obrador se estaba "burlando de los ciudadanos, para [...] seguir en una campaña política sin fin y cualquier tema lo usa para desprestigiar a la oposición en lugar de actuar responsablemente según el problema que se le presenta" (González, 2020). Por tanto, se argumentó, el presidente buscaba ganar beneficios políticos y popularidad que después podría aprovechar en términos electorales: le "importa más la popularidad personal que la viralidad letal. Su narcisismo le gana a su patriotismo [...] al actuar irresponsablemente como lo hace [...], AMLO se vuelve el antihéroe" (Dresser, 2020). En este sentido, en una columna en el Excélsior se dijo que "de hacer cálculos políticos, su popularidad pasa a segundo término cuando lo que está en peligro es la salud del país" (Esquinca, 2020).

Durante este tiempo $T_{1}$, el presidente fue acusado tanto de mostrar una actitud irracional como calculadora frente a la pandemia. La Jornada Nacional de Sana Distancia se interpretó como una estrategia insuficiente o tardía. Las atribuciones inciviles de las que el presidente fue objeto acusaron que era un político incapaz de enfrentar un escenario de emergencia sanitaria. Estas críticas no eran muy distintas de aquellas que acusaban a López Obrador de ser una persona que se movía por sus pasiones, preocupado constantemente por mantener su imagen a través de polarizar a la sociedad. Estas críticas habrían de convertirse en un problema de disfuncionalidad institucional cuando el titular del Ejecutivo se mostró con la pureza moral y espiritual suficiente para estar por encima de la Covid-19. 


\section{Societalización: la irracionalidad amenazante}

El 16 de marzo se le preguntó al presidente si era necesario que mantuviera la sana distancia en sus eventos públicos y si se realizaría las pruebas para saber si estaba contagiado de Covid-19; López Obrador arguyó que se sujetaría al protocolo necesario y pidió a López-Gatell que explicara por qué no era necesaria la prueba y por qué no debía cancelar sus eventos públicos. El subsecretario respondió que la demanda de hacer pruebas, ya sea al presidente o los ciudadanos, "parte de una visión totalmente fuera de lugar en términos científicos [...] lo cual es algo carente de sentido técnico" (Grupo Reforma, 2020). Y agregó: "no sirve de nada saber [si un enfermo] es positivo o negativo" porque la atención médica por Covid-19 es exactamente igual si se tiene o no la enfermedad. López-Gatell afirmó que el presidente tenía derecho a la privacidad y no podía ser forzado a realizarse una prueba de Covid-19. Además, agregó el subsecretario, el presidente goza de plena salud y "sería mejor si padeciera coronavirus porque lo más probable es que él en lo individual, como la mayoría de las personas, se va a recuperar espontáneamente y va a quedar inmune." Y sentenció, "la fuerza del presidente es moral no es una fuerza de contagio, el presidente no es una fuente de contagio que pueda contagiar a las masas" (Grupo Reforma, 2020).

Lo anterior disparó una serie de críticas al subsecretario: se le acusó de carecer de autonomía frente al presidente y de transformar su cargo en un medio al servicio del Ejecutivo federal. A decir de una columna en Excélsior, López-Gatell "perdió credibilidad al justificar todas las transgresiones con cantinflescas maromas, asegurando que la 'fuerza' del presidente es 'moral' y no de 'contagio'”' (Belaunzarán, 2020). En Milenio, un columnista acusó al subsecretario de abyección, "al atribuir al presidente de la República poderes tan inauditos como metafísicos, que se antojan superiores a los concedidos por sus vasallos a caudillos en países donde se cultiva el repugnante culto a la personalidad" (Marín, 202Ob).

De esta forma, López-Gatell dejó de ser un experto, se comentó en Reforma, para "quedar bien con el jefe y demuestra una devoción que linda en lo religioso" (Sarmiento, 2020). Por tanto, Hugo López-Gatell, señaló un articulista de Milenio, "ensucia su trayectoria con la ignominiosa mancha de la lambisconería" (Martínez, 2020). En el Reforma se argumentó su nula independencia frente al titular del Ejecutivo: "al académico le faltó carácter y optó por agachar la cabeza ante la voluntad presidencial" (Aguayo, 2020). Así, se dijo en El Universal, el "científico ha sido contagiado por el virus del poder y la bacteria de la veneración, y sin querer abonó al diccionario de la picaresca política" (Rocha, 2020)." Sin embargo, más preocupante que la imagen de López-Gatell era, según una columnista del Reforma, su desdén dilatorio que ha costado tiempo valioso, "durante el cual se pudieron haber tomado medidas de mayor contundencia" (Dresser, 2020).

Dos días después, se volvió a cuestionar al presidente sobre la conveniencia de que participara en eventos masivos. El presidente aseguró que tenía un escudo protector:

"un escudo protector es como el detente 2 [...], el escudo protector es la honestidad, eso es lo que protege, sí, el no permitir la corrupción. Miren, aquí está el detente [mostrando unos amuletos a las cámaras]. Es que me los dan, son mis guardaespaldas, porque no están demás. Aquí esta otro detente [muestra otro amuleto que saca de su cartera]: 'detente, enemigo, que el Corazón de Jesús está conmigo"' (Grupo Reforma, 2020).

\footnotetext{
11 También se señaló que el comportamiento de López-Gatell se debía a que respondía a intereses económicos: "al subsecretario le da por distraerse de su responsabilidad poniendo más interés en el dinero que en sus obligaciones" (Marín, 2020a).

12 El detente es una imagen del Sagrado Corazón de Jesús conformada por un corazón rodeado de la corona de púas con la que fue coronado Jesús -según la tradición católica- en su crucifixión. Dicha imagen se presenta según se reveló a Santa Margarita María de Alacoque. La leyenda que rodea la imagen dice "Detente, el Corazón de Jesús está conmigo" y tiene por función proteger a quien lo porte.
} 
Esto desató una serie de críticas que insistían en resaltar el carácter irracional con que López Obrador trataba la pandemia. Incluso, en La Jornada -un periódico que tradicionalmente ha respaldado al presidente- se advirtió que "más allá del laicismo y el respeto que el presidente y su gobierno le deben, la invocación presidencial de este miércoles parece sobre todo una invitación a hacer de la irracionalidad la forma de hacer y entender la política" (Cordera, 2020). Un columnista de La Jornada sentenció que "el comportamiento de AMLO es doblemente irresponsable: primero, porque se arriesga a contraer el Covid-19, lo que, dada su edad y sus antecedentes cardiacos, es altamente riesgoso. La crisis política que viviría el país si falleciera sería un verdadero apocalipsis" (Boltvinik 2020). Así, su comportamiento fue censurado en términos de las desastrosas secuelas que podría traer su muerte para la política nacional.

Para otras voces, lo más preocupante era que las creencias del presidente generaban lealtades hasta tal punto que es "penoso ver a sus allegados arrastrarse en la más vil servidumbre y abyecto fanatismo" (Blancarte, 2020). Para algunos columnistas, la confianza del presidente de estar más allá de la pandemia tenía efectos reales en la salud de la población. En una columna de Milenio se señaló que su comportamiento "vacila entre la irresponsabilidad y la negligencia" (Acevedo, 2020). Desde una columna de Excélsior se dijo, por ejemplo, que "López Obrador da muestras de escasa conexión con la gravedad de la situación o incapacidad de liderazgo para ver problemas que escapan a una narrativa monotemática" (Buendía Hegewisch, 2020). Una columna del Reforma argumentó que "mientras otros líderes se crecen ante la adversidad, el nuestro nos muestra las estampitas protectoras en su cartera" (Suárez-Vélez, 2020). A decir de una columna de El Universal, "la falta de actuación de nuestras autoridades [...] ante el COVID19 va a ocasionar muchas muertes y como siempre, las cifras serán mayores entre los más vulnerables" (Limón García, 2020). Un columnista del Reforma senten- ció: "López Obrador es un líder irresponsable" (Rangel, 2020).

En esta etapa de societalización de la pandemia $\left(T_{2}\right)$, los cuestionamientos subrayaron las contradicciones y tensiones al interior del gobierno al gestionar el riesgo que enfrentaba el país. En el proceso de construcción de sentido de la crisis, la societalización trabajó críticamente sobre lo que consideró la falencia fundamental de López Obrador y López-Gatell: el carácter irracional del primero y la subordinación del segundo al poder del presidente. Sin embargo, en esta etapa comenzaron a escucharse reacciones de apoyo al presidente, como se señaló en una columna en La Jornada:

un elemento muy importante en el diseño de la ruta obradorista respecto al coronavirus es el entendimiento de la condición socioeconómica sumamente vulnerable de la mayoría de la población nacional a la que afectaría muy duramente, a niveles incluso de potencial incumplimiento de órdenes, la cadena de restricciones que en otros países se han instaurado (Hernández, 2020).

En este posicionamiento se resaltaba que la lentitud con la que se estableció la política de sana distancia buscó salvaguardar la actividad económica de los sectores sociales más pobres y marginados e, incluso, sugirió que para estos últimos no aplicarían las restricciones que se exigían a los grupos de clase media y alta.

\section{Reparación de daños y reacciones reinstituyentes}

Las críticas al subsecretario de Salud por el manejo de la pandemia, la supuesta superioridad moral y el halo de protección mística del presidente no se tradujeron en sanciones o llamados de atención a estos funcionarios $\left(\mathrm{T}_{3}\right)$. Incluso, estos últimos no ofrecieron ninguna aclaración por sus dichos. Para el 24 de marzo, el gobierno declaró que el país entraba en la fase 2 de la pandemia. Esto implicaba que los casos de contagio ya no eran sólo de importación. López-Ga- 
tell llamó a mantener la calma y aseguró que la pandemia únicamente duraría 12 semanas, "porque fue lo que duró en China" (Miranda et al., 2020). El subsecretario añadió que se había planeado la estrategia de salud desde finales de febrero, por lo que era posible doblar la curva de crecimiento de la pandemia. El objetivo en la nueva fase de contagio, a decir del subsecretario, era reforzar las medidas de la Jornada $\mathrm{Na}$ cional de Sana Distancia, a fin de que cada día hubiera menos enfermos en los hospitales. Según López-Gatell, muchos países tenían millares de muertes, pero en México sólo había cuatro fallecidos. México, sostuvo el subsecretario, aprovechará esta área de oportunidad para frenar la pandemia con base en elementos científicos (Miranda et al., 2020). Al día siguiente, Cristian Morales, representante en México de la Organización Panamericana de la Salud, aseguró que México iba por buen camino en el combate a la pandemia.

Los críticos del gobierno aseguraron que el establecimiento de la fase 2 representó el reconocimiento tardío e inadecuado del problema. Para este posicionamiento, el presidente no asumía el riesgo de la Covid-19. Desde una columna del Reforma se acusó que López Obrador "invita a caminar con ritmo lento, 'a su tiempo', [...] mientras los síntomas de [la] crisis se expanden" (Chertoriski, 2020). Se dijo, desde El Universal, que aun cuando el presidente reconoció que el país entró en la fase de contagio local, se "sigue sin tomar en serio las medidas de aislamiento social recomendadas por los expertos" (Márquez, 2020). Se argumentó desde una columna de Milenio: "la negación es método y el presidente lo suscribe con singular persistencia. Muy terco, como él mismo se dice. El presidente cambió el viernes de discurso y actitud. Encomiable, pero muy tarde. Hace un mes hubiera sido eficaz" (Berrueto, 2020b). La posición y actitud del presidente, se dijo en una columna de Excélsior, se transmite a su propio subsecretario de Salud, quien prefiere ser leal al ejecutivo: no puede ser al mismo tiempo epidemiólogo y lamebotas del presidente, no señala lo que se debe hacer y calla ante las exhibiciones de amuletos (Álvarez, 2020).

A diferencia del momento $T_{2}$, es posible observar en la prensa argumentos a favor del presidente. Se subrayó el carácter científico y técnico de la estrategia del gobierno, se enfatizó el reconocimiento que dieron al presidente los organismos internacionales, así como la heroicidad con la que subsecretario de Salud afrontó la pandemia. De esta forma se trataron de imputar a López Obrador y a López-Gatell las atribuciones de la pureza civil, al considerarlos como personas autónomas, racionales y realistas frente a la pandemia. Se les juzgó como funcionarios transparentes al escrutinio público, operando las instituciones a su cargo de manera impersonal e incluyente. Así, por ejemplo, en Milenio se pudo leer:

desde que se confirmó el brote del nuevo coronavirus en China, se adoptó la política de informar, no alarmar; de monitorear la pandemia, no de precipitar acciones; y dejar en manos de especialistas de salud pública las decisiones por tomar. La OMS [Organización Mundial de la Salud] ha señalado que el gobierno de México está cumpliendo en tiempo y forma las principales medidas de prevención, y que tiene la capacidad técnica y hospitalaria para enfrentar la emergencia (Monreal, 2020).

Con respecto a la calidad técnica y científica con la que se había manejado la Covid-19, se podía leer en La Jornada que el presidente "mereció el reconocimiento de la Organización Mundial de la Salud" (Miguel, 2020). Además, se enfatizó en una opinión suscrita en Milenio, el gobierno no actuó a destiempo, midió los tiempos para controlar la pandemia, siempre siguiendo los criterios científicos en beneficio de la población en general, pero en particular de los menos favorecidos (Becerra-Acosta, 2020).

Desde La Jornada, una de las escritoras más reconocidas del país, Elena Poniatowska (2020), suscribió que "a través de sus conferencias estupendamente bien documentadas y dichas con severidad, el doctor Hugo López-Gatell se está convirtiendo a 
pasos agigantados en Superman, Batman y Tarzán”.

Tanto el presidente como el subsecretario de Salud fueron imputados por sus simpatizantes con las atribuciones que los convertían en héroes civiles. En contraste con las voces críticas, quienes defendieron a López Obrador y López-Gatell sugirieron que ambos permitían que las instituciones de salud pública funcionaran adecuadamente. Así, estas voces trataron de restablecer la pureza de la esfera estatal encabezada por López Obrador $\left(\mathrm{T}_{4}\right)$. A partir de aquí, la societalización de la pandemia perdió fuerza y las críticas al carácter irracional del presidente y del subsecretario fueron desplazadas por aquellas que subrayaron su comportamiento errático y carente de iniciativa, generando un nuevo Estado estable $\left(T_{5}\right)$.

Durante 2020 se han presentado distintos intentos por societalizar la pandemia. Cuando López-Gatell aseguró que el cubrebocas no servía más que "para dar una falsa sensación de seguridad", cuando días antes los organismos internacionales habían sugerido su uso (Ordóñez, 2020). Otra controversia se generó al anunciar que el manejo de la epidemia sería a través de un semáforo de riesgo epidemiológico y después afirmó que el "color del semáforo era intrascendente" y no servía para tomar decisiones ( $E x$ pansión Política, 2020b). En otro momento, López-Gatell aseguró que la pandemia no se saldría de control y que sólo en un escenario muy catastrófico el número de muertes llegaría a los 60,000 decesos; cuando esta cifra se rebasó, acusó que se debía a la obesidad, hipertensión y diabetes de la población, y responsabilizó al neoliberalismo de imponer un sistema alimentario basado en productos ultraprocesados, altos en azúcares y grasas. Cuando Mike Ryan, director de Emergencias de la Organización Mundial de la Salud, aseguró que el desastre de la pandemia en México se debió al bajo número de pruebas realizadas en el país, López-Gatell afirmó que las pruebas "no sirven y representan un gasto innecesario de dinero".

Por supuesto, López Obrador protagoni- zó momentos que generaron oportunidades de societalización. Cuando The New York Times, Wall Street Journal y El País advirtieron que el número de fallecidos era mayor al que reportaban las autoridades federales, el presidente acusó que detrás de esos periódicos había intereses oscuros, de conservadores y neoliberales, que buscaban afectar su proyecto político, e insistió que la "pandemia estaba domada". ${ }^{3}$ Sin embargo, en las sociedades polarizadas no es suficiente evidenciar la existencia de amenazas a la solidaridad social para disparar los procesos de societalización. Esto se debe a que en dichos contextos las audiencias no comparten un estándar común de evaluación civil. Una encuesta publicada a finales de 2020 dejó constancia de la falta de ese estándar común: $55 \%$ de los ciudadanos aprobó la gestión de la pandemia, frente a $45 \%$ que la desaprobó (González y Guerrero, 2020). Así, la sociedad mexicana parece que tiene dos referentes interpretativos sobre lo que significa poner en riesgo a la población.

\section{Conclusión}

El proceso de societalización de la pandemia terminó con un nuevo Estado estable. Por un lado, los críticos al gobierno volvieron a concentrar sus comentarios en la dilación e ineficiencia de las acciones del presidente y su subsecretario de Salud. Por otro lado, los simpatizantes de ambos funcionarios insisten en mostrar la adecuada gestión de la pandemia, sus bases científicas y técnicas, así como el compromiso social detrás de ella. Los posicionamientos críticos no han traducido la actuación de López Obrador y de López-Gatell como una disfuncionalidad institucional profunda que amenace la salud pública y mucho menos han logrado

\footnotetext{
13 Cabe destacar que, a principios de 2021, López-Gatell resultó positivo a Covid-19 y tuvo que ser hospitalizado. La polémica se profundizó cuando, aún estando en condiciones de contagiar a otras personas, paseó por parques públicos y zonas de restaurantes, violentando con su conducta las propias recomendaciones emitidas por él en su calidad de autoridad sanitaria. El presidente defendió el comportamiento del subsecretario señalando que las situaciones eran "accesorias" a su función y al trabajo que realiza.
} 
imponer a ambos funcionarios regulaciones y sanciones a sus comportamientos. Por su parte, quienes han manifestado su apoyo al presidente y su política de salud sostienen que existe la suficiente fortaleza institucional para vencer la pandemia. La dinámica de polarización que vive el país ha contribuido a que las posiciones encontradas se confronten a tal punto de que la societalización no ha logrado crear un estándar común de evaluación sobre lo que significa una adecuada gestión de la pandemia.

Sin embargo, la societalización de la pandemia evidenció las tensiones sobre el supuesto carácter civil e incivil del presidente y su subsecretario de Salud. Ambos fueron juzgados, ya sea por su pretensión de sostener una solidaridad social ampliada o reducida. Para quienes apoyaron la gestión de la pandemia, el presidente generó una política inclusiva y científicamente sustentada de salud de la población. Para los críticos de la gestión de la pandemia, el presidente impulsó una política excluyente y científicamente débil, que restringe el acceso a la salud a la mayor parte de la población. Para los primeros, el presidente ha sido capaz de garantizar las bases para desarrollar una colectividad solidaria, donde los ciudadanos tengan acceso universal a un amplio número de beneficios sociales. Para los segundos, las decisiones del presidente no permiten garantizar una colectividad solidaria y más bien reducen la posibilidad de que los ciudadanos accedan a los beneficios sociales de las instituciones de salud.

El aporte de la teoría de la societalización, en el marco de la teoría de la esfera civil, al análisis sociológico de la pandemia, es que permite comprender cuándo los funcionarios a cargo de la gestión de las políticas de salud son juzgados como una amenaza a la salud pública, a tal punto que se considera que pueden destruir los lazos de solidaridad y las membresías de inclusión social. En otras palabras, permite examinar cómo los funcionarios son colocados bajo el escrutinio de las instituciones comunicativas y regulativas de la esfera civil. Este tipo de análisis desvela procesos que no han sido abordados por estudios previos que se han centrado en examinar la supuesta efectividad de las acciones estatales para controlar la pandemia en términos de política pública, dispositivos de vigilancia, estilos y discursos del poder. Estos estudios ignoran cómo se disputa el control por el sentido de la gestión de la pandemia. Este énfasis resulta importante porque permite subrayar cómo se construyen los sentidos de solidaridad, de inclusión y exclusión social, pero también permiten entender las disputas que se abren con la llamada nueva normalidad pospandemia.

\section{Referencias}

Abidin, Crystal y Zeng, Jing (2020), "Feeling Asian Together: Coping With \#COVIDRacism on Subtle Asian Traits", Social Media + Society, 6 (3), SAGE, doi:10.1177/2056305120948223

Acevedo, Enrique (2020), "La moral y el virus", Milenio, 19 de marzo, Ciudad de México, Grupo Milenio, Opinión Nacional, <https://bit.ly/3fGLzxU>, 20 de mayo de 2021.

Agamben, Giorgio (2020), "La invención de una pandemia", Ficción de la razón, 27 de febrero, Ficción de la razón, Filosofía-Política, <https://bit.ly/3yshg6C>, 28 de diciembre de 2020.

Aguayo, Sergio (2020), "Viviendo España", Reforma, 18 de marzo, Ciudad de México, Grupo Reforma, Opinión, <https:// bit.ly/3fAnake>, 20 de mayo de 2021.

Aguilar Camín, Héctor (2020a), "INE: Ia cirugía dura", Milenio, 29 de enero, Ciudad de México, Grupo Milenio, Opinión Nacional, <https://bit.ly/3hsQjJX>, 16 de mayo de 2021.

Aguilar Camín, Héctor (2020b), "Coronavirus: preciosos días perdidos", Milenio, 16 de marzo, Ciudad de México, Grupo Milenio, Opinión Nacional, < https:// bit.ly/3wkLZAD>, 20 de mayo de 2021. 
Agúndez Márquez, Roberto (2020), "Y no dejemos de congregarnos... Adecuaciones a la práctica de congregarse de tres iglesias cristianas evangélicas durante la pandemia de COVID-19 en Mexicali, México", Revista Culturales, 8, e537, doi:10.22234/recu.20200801.e537

Alexander, Jeffrey (2006), The Civil Sphere, Oxford, Oxford University Press.

Alexander, Jeffrey (2018), "The Societalization of Social Problems: Church Pedophilia, Phone Hacking, and the Financial Crisis", American Sociological Review, 83 (6), American, Sociological Association, 1049-1078.

Alexander, Jeffrey (2020), What makes a social crisis? The societalization of Social Problems, Cambridge, Polity.

Alimardani, Mahsa y Elswah, Mona (2020), "Online Temptations: COVID-19 and Religious Misinformation in the MENA Region", Social Media + Society, 6 (3), SAGE, doi: 10.1177/2056305120948251

Alon, Ilan; Farrell, Matthew y Li, Shaomin (2020), "Regime Type and COVID-19 Response", FllB Business Review, 9 (3), Nueva Delhi, Fortune Institute of International Business, pp. 152-160, doi:10.1177/2319714520928884

Álvarez Cordero, Rafael (2020), "Cómo destruir un sistema", Excélsior, 29 de marzo, Ciudad de México, Excélsior, Opinión, < https://bit.ly/3bJyOfO>, 20 de mayo de 2021.

Arteaga Botello, Nelson (2021), "The populist transition and the Civil Sphere in Mexico" en Jeffrey Alexander, Peter Kivisto y Giuseppe Sciortino (eds.), Populism in the Civil Sphere, Cambridge, Polity.

Arteaga Botello, Nelson y Cardona Acuña, Luz Ángela (2020), "La significación intelectual de la pandemia Covid-19", Sociológica, 100 (35), México, Universidad Autónoma Metropolitana, pp. 77-84.

Balmori de la Miyar, Jose; Hoehn-Velasco, Lauren y Silverio-Murillo, Adan
(2020), "Druglords don't stay at home: COVID-19 pandemic and crime patterns in Mexico City", J Crim Justice, 101745, NCBI, doi: 10.1016/j.jcrimjus.2020.101745.

Becerra-Acosta, Juan Pablo (2020), "\#Coronavirus, buen gobierno y ruindad”, Milenio, 23 de marzo, Ciudad de México, Grupo Milenio, Opinión Nacional, <https://bit.ly/342hK5p>, 20 de mayo de 2021

Báez, José Francisco y Ruíz, Octavio (2020), "Educación virtual y su marco regulatorio en México ante la emergencia sanitaria por COVID-19", Universos Jurídicos, 14 (2), Xalapa, Universidad Veracruzana, pp. 36-60.

Belaunzarán, Fernando (2020), "El odio en los tiempos del coronavirus", Excélsior, 17 de marzo, Ciudad de México, Excélsior, Opinión, <https://bit.ly/3ysOQLt>, 20 de mayo de 2021.

Berrueto, Federico (2020a), “¿Qué le pasa al Presidente?", Milenio, 15 de marzo, Ciudad de México, Grupo Milenio, Opinión, <https://bit.ly/3bF1Z8H>, 20 de mayo de 2021.

Berrueto, Federico (2020b), "Primera línea de batalla", Milenio, 29 de marzo, Ciudad de México, Grupo Milenio, Opinión, <https://bit.ly/3ytRTkN>, 20 de mayo de 2021.

Binder, Werner (2021), "Memory Culture, the Civil Sphere, and Right-Wing Populism in Germany" en Jeffrey Alexander, Peter Kivisto y Giuseppe Sciortino (eds.), Populism in the Civil Sphere, Cambridge, Polity.

Blancarte, Roberto (2020), "El Titanic Ilamado 4T", Milenio, 24 de marzo, Ciudad de México, Grupo Milenio, Opinión, <https://bit.ly/3oEgoql>, 20 de mayo de 2021.

Boltvinik, Julio (2020), "Economía moral", La Jornada, 20 de marzo, Ciudad de México, DEMOS, Opinión, <https://bit. ly/3bJJi3G>, 20 de mayo de 2021. 
Buendía Hegewisch, José (2020), "El Presidente, con la fe de un iluso", Excélsior, 19 de marzo, Ciudad de México, Excélsior, Opinión, < https://bit.ly/3yu9tFq>, 20 de mayo de 2021.

Butler, Elizabeth y Luengo, María (2016), "Conclusion: news innovation and enduring commitments" en Jeffrey Alexander, Elizabeth Butler y María Luengo (eds.), The Crisis of Journalism Reconsidered, Cambridge, Cambridge University Press, pp. 282-290.

Cardona Acuña, Luz Ángela y Arteaga Botello, Nelson (2020), "No me cuidan, me violan: la esfera civil y la protesta feminista", Región y Sociedad, 32, Hermosillo, El Colegio de Sonora, e1345, doi:10.22198/rys2020/32/1345

Cepaluni, Gabriel; Michael Dorsch y Reka Branyiczki (2020), "Political Regimes and Deaths in the Early Stages of the COVID-19 Pandemic", SSRN, <https:// ssrn.com/abstract=3586767>, 20 de diciembre de 2020.

Chertorivski, Salomón (2020), "Covid-19: respuesta masiva", Reforma, 27 de marzo, Ciudad de México, Grupo Reforma, Opinión, <https://bit.ly/3f7ExmL>, 20 de mayo de 2021.

Collins, Randall (2020), "Social distancing as a critical test of the micro-sociology of solidarity", American Journal of Cultural Sociology, 8, pp. 477-497, doi: 10.1057/ s41290-020-00120-z

Cordera Campos, Rolando (2020) "El abandono del tiempo", La Jornada, 22 de marzo, Ciudad de México, DEMOS, Opinión, <https://bit.ly/346bDNw>, 20 de mayo de 2021.

Cottle, Simon (2004), The Racist Murder of Steven Lawrence: Media Performance and Public Transformation, Westport, SAGE.

Demertzis, Nicolas y Eyerman, Ron (2020), "Covid-19 as cultural trauma", American Journal of Cultural Sociology, 8, pp. 428450, doi:10.1057/s41290-020-00112-z
Douglas, Mary (1966), Purity and Danger: An Analysis of Concepts of Pollution and Taboo, Nueva York, Praeger.

Dresser, Denise (2020), "El antihéroe", Reforma, 16 de marzo, Ciudad de México, Grupo Reforma, Opinión, <https://bit. ly/342yoBV>, 20 de mayo de 2021.

Earl, Jennifer; Martin, Andrew; McCarthy, Jhon y Soule, Sarah (2004), "The use of newspaper data in the study of collective action", Annual Review of Sociology, 30, pp. 65-80, doi:10.1146/annurev. soc.30.012703.110603

El Universal (2019), "Reprueban manejo de combate a la inseguridad", El Universal, noviembre, Ciudad de México, El Universal, <https://bit.ly/2Qqru6g>, 16 de mayo de 2021.

Esquinca, Vianey (2020), "¿Otra vez, presidente?", Excélsior, 15 de marzo, Ciudad de México, Excélsior, Opinión, <https:// bit.Iy/3hNaTES>, 20 de mayo de 2021.

Expansión Política (2020a), "AMLO cierra el 2019 con un 72\% de aprobación, según encuesta", Expansión Política, 6 de enero, Ciudad de México, Expansión, México, <https://bit.ly/3byy6ll>, 16 de mayo de 2021.

Expansión Política (2020b), "El color del semáforo en la CDMX 'es intrascendente', dice López-Gatell”, Expansión Política, 11 de diciembre, Ciudad de México, Expansión, México, <https://bit.ly/3bA1Vqy>, 16 de mayo de 2021.

Farge, Arlette (1994), Subversive Words: Public opinion in Eighteenth Century in France, Cambridge, Polity.

Fernández de Cevallos, Diego (2020), "Voluntarismo puro y puro voluntarismo", Milenio, 16 de marzo, Ciudad de México, Grupo Milenio, Opinión Nacional, < https://bit.ly/3fviQfe>, 20 de mayo de 2021.

Fernández Menéndez, Jorge (2020), "Pandemia: en busca del tiempo perdido", Excélsior, 17 de marzo, Ciudad de Mé- 
xico, Excélsior, Opinión, <https://bit. ly/3hKeyn8>, 20 de mayo de 2021.

Garrido de Sierra, Sebastián (2020), "Las astucias vespertinas de López-Gatell", Nexos, 1 de noviembre, Ciudad de México, Nexos, <https://bit.ly/3op2NUj>, 16 de mayo de 2021.

Gómez, Leopoldo (2020), "Hacia un nuevo sistema de salud", Milenio, 14 de enero, Ciudad de México, Grupo Milenio, Opinión nacional, <https://bit.ly/3tSKPL8>, 16 de mayo de 2021.

González, Isabella y Guerrero, Claudia (2020), "Cucharea Reforma encuesta'; dice AMLO tener otros datos", Reforma, 31 de agosto, Ciudad de México, Grupo Reforma, Libre acceso, <https:// bit.ly/3tWOnh3>, 16 de mayo de 2021.

González, Maritza (2020), "Alarma real”, Reforma, 15 de marzo, Ciudad de México, Grupo Reforma, Opinión, <https://bit. ly/3u6rO2L>, 20 de mayo de 2021.

Grupo Reforma (2020), "Fuerza de AMLO es moral, no de contagio: López-GateII", [YouTube], 16 de marzo, <https:// bit.ly/2SQZMAh>, 16 de mayo de 2021.

Gutierrez, Cristina y De la Torre, Renée (2020), "Covid-19: la pandemia como catalizador de la videogracia", Espiral Estudios sobre Estado y Sociedad, 27 (78-79), OJS/PKP, Guadalajara, Universidad de Guadalajara, doi: 10.32870/ eees.v28i78-79.7205

Han, Byung-Chul (2020), "La Emergencia Viral y el Mundo del Mañana", El País, 22 de marzo, Ediciones El País, España, Ideas, <https://bit.ly/3hw2zZY>, 27 de diciembre de 2020.

Hernández López, Julio (2020), "Astillero", La Jornada, 19 de marzo, Ciudad de México, DEMOS, Opinión, <https://bit. ly/3wsfjVF>, 20 de mayo de 2021.

Jacobs, Ronald (1996), "Civil Society and Crisis: Culture, Discourse, and the Rodney King Beating", American Journal of So- ciology, 101 (5), The University of Chicago Press, pp. 1238-1272, <www.jstor. org/stable/2782354>, 29 de diciembre de 2020 .

Jardínez Hernández, Rocío (2020), "Mucho ojo... ahora los conservadores se dicen feministas: AMLO", W Radio, 21 de febrero, Ciudad de México, Radiópolis, Nacional, <https://bit.ly/2QnT9Vk>, 16 de mayo de 2021.

Kivisto, Peter y Sciortino, Giuseppe (2019), "Conclusion: reflections on radicalism and the civil sphere", en Jeffrey Alexander, Trevor Stack y Farhad Khosrokhavar (eds.), Breaching the Civil Order: Radicalism and the Civil Sphere, Cambridge, Cambridge University Press, pp. 268-284.

Kivisto, Peter, y Sciortino, Giuseppe (2015), "Introduction: thinking the civil sphere", en Peter Kivisto y Giuseppe Sciortino (eds.), Solidarity, Justice and Incorporation, Oxford, Oxford University Press, pp. 1-30.

Latour, Bruno (2020), "Is this a Dress Rehearsal", Critical Inquiry, 26 de marzo, Critical Inquiry, In the moment, <https://bit.ly/2RoBDAR>, 28 de diciembre de 2020.

Limón García, Lía (2020), "La popularidad, antes que la pandemia”, El Universal, 19 de marzo, Ciudad de México, El Universal, Opinión, <https://bit.ly/3u6rPsn>, 20 de mayo de 2021.

Lo, Ming-Cheng y Hsieh, Hsin-Yi (2020), "The "Societalization" of pandemic unpreparedness: lessons from Taiwan's COVID response", American Journal of Cultural Sociology, pp. 384-404, doi: $10.1057 / s 41290-020-00113-y$

Malhotra, Pranav (2020), "A Relationship-Centered and Culturally Informed Approach to Studying Misinformation on COVID-19", Social Media + Society, 1 (4), SAGE, doi: 10.1177/2056305120948.

Marchal, Naema y Hubert, Au (2020), "'Coronavirus EXPLAINED': You- 
Tube, COVID-19, and the Socio-Technical Mediation of Expertise", Social Media + Society, 1 (4), SAGE, doi: $10.1177 / 2056305120948$

Marin, Carlos (2020a), "Un 'zar' contra el coronavirus", Milenio, 16 de marzo, Ciudad de México, Grupo Milenio, Opinión, <https://bit.ly/2RzYGIU>, 20 de mayo de 2021.

Marin, Carlos (2020b), "Enfoque "técnico" de la abyección", Milenio, 17 de marzo, Ciudad de México, Grupo Milenio, Opinión, <https://bit.ly/34bxfaZ>, 20 de mayo de 2021.

Márquez, Solange (2020), "Brasil y México frente a la pandemia, un discurso letal", El Universal, 26 de marzo, Ciudad de México, El Universal, Opinión, <https:// bit.ly/2Sd2P5M>, 20 de mayo de 2021.

Martínez, José Luis (2020), "Ciudades desiertas", Milenio, 22 de marzo, Ciudad de México, Grupo Milenio, Opinión, <https://bit.ly/3bl2xum>, 20 de mayo de 2021.

Mast, Jason (2019), "Introduction: Fragments, Ruptures, and Resurgent Structures: The Civil Sphere and the Fate of "Civilship" the Era of Trumpism", en Jason Mast y Jeffrey Alexander (eds.), Politics of Meaning/Meaning of Politics, Palgrave Macmillan, Cham, pp. 1-16.

McCarthy, John; McPhail, Clarck y Smith, Jackie (1996), "Images of protest: dimensions of selection bias in media coverage of Washington demonstrations, 1982 and 1991", American Sociological Review, 61 (3), American Sociological Association, pp.478-499, doi: 10.2307/2096360

McCormick, Lisa (2020), "Marking time in lockdown: heroization and ritualization in the UK during the coronavirus pandemic", American Journal of Cultural Sociology, 8, pp. 324-351, doi:10.1057/ s41290-020-00117-8

Miguel, Pedro (2020), "En medio de la epidemia, la 4T avanza", La Jornada, 27 de marzo, Ciudad de México, La Jornada, Opinión, <https://bit.ly/3v8visO>, 20 de mayo de 2021.

Milan, Stefania y Treré, Emiliano (2020), "The Rise of the Data Poor: The COVID-19 Pandemic Seen From the Margins", Social Media + Society, 1 (5), SAGE, doi:10.1177/2056305120948233

Miranda, Perla; Morales, Alberto y Villa y Caña, Pedro (2020), "México entra a fase 2 por coronavirus", El Universal, 24 de marzo, Ciudad de México, El Universal, Nación, <https://bit.ly/3bx92jP>, 16 de mayo de 2021.

Monreal Ávila, Ricardo (2020), "Influenza (2009) vs coronavirus (2020)", Milenio, 24 de marzo, Ciudad de México, Grupo Milenio, Opinión, <https://bit.ly/3oHm5UX>, 20 de mayo de 2021.

Morgan, Marcus (2020), "Why meaning-making matters: the case of the UK Government's COVID-19 response", American Journal of Cultural Sociology, 8 , pp. 270-323, doi: 10.1057/s41290-02000121-y

Murillo, Andrea (2020), "Desconfianza, regímenes de verdad, conspiraciones y montajes en el contexto de la COVID-19 en México", Desde el Sur, 12 (2), Lima, Universidad Científica del Sur, pp. 547-571, doi: 10.21142/DES-1201-20200030 .

Nájar, Alberto (2020), "Caso Fátima: cómo la respuesta de AMLO ante los feminicidios se convirtió en una crisis para su gobierno", BBC Mundo, 21 de febrero, Ciudad de México, BBC, América Latina, <https://bbc.in/33N6LwD>, 16 de mayo de 2021.

Ordaz, Yeshua (2020), “¿Por qué cayó el precio del petróleo y en qué afecta a México?", Milenio, 10 de marzo, Ciudad de México, Grupo Milenio, Negocios, <https://bit.ly/3bwkyfb>, 16 de mayo de 2021.

Ordóñez, Caleb (2020), "\#ZonaLibre La catástrofe de Hugo López-Gatell”, Expan- 
sión Política, 16 de diciembre, Ciudad de México, Expansión, Voces, <https:// bit.ly/33MyFZD>, 16 de mayo de 2021.

Ordóñez Barba, Gerardo (2020), "Tijuana ante el confinamiento social impuesto por la covid 19: habitabilidad de las viviendas, entorno urbano y condiciones económicas de los hogares", Espiral Estudios sobre Estado y Sociedad, vol. 27 (78-79), Guadalajara, Universidad de Guadalajara, OJS/PKP, doi:10.32870/ eees.v28i78-79.7209.

Ortíz-Arellano, Edgar (2020), "México ante el COVID-19: Seguridad humana, gubernamentalidad y biopolítica", Escuela de Ciencias Sociales y Humanidades, Vol. 20 (40), doi:10.22458/re.v20i40.3338.

Park, Soonwoong (2019), "System Crisis and the Civil Sphere", en Jeffrey Alexander, David Palmer, Sunwoong Park y Agnes Shuk-mei Ku (eds.), The Civil Sphere in East Asia, Cambridge, Cambridge University Press, pp. 38-59.

Peña, Victor (2020), "Preparados para un virus nocturno: coronavirus, decisiones de política pública y vulneración de derechos en cinco municipios de Sonora, México", Región y Sociedad, 32, e1324, doi: 10.22198/rys2020/32/1324.

Poniatowska, Elena (2020), "Pandemia", La Jornada, 27 de marzo, Ciudad de México, DEMOS, Opinión, <https://bit. |y/344d6nl>, 20 de mayo de 2021.

Rangel, Alejandra (2020), "Las Pestes", Reforma, 21 de marzo, Ciudad de México, Grupo Reforma, Opinión, <https://bit. ly/2SfVzFY>, 20 de mayo de 2021.

Rentería, Cesar y Arellano-Gault, David (2020), "How does a populist government interpret and face a health crisis? Evidence from the Mexican populist response to COVID-19", Brazilian Journal of Public Administration, Rio de Janeiro, Fundación Getulio Vargas, <https:// bit.ly/3omVZX6>, 29 de diciembre de 2020.
Rocha, Ricardo (2020), "El virus, el contagio y la doctrina", El Universal, 18 de marzo, Ciudad de México, El Universal, Opinión, <https://bit.ly/3yt9B82>, 20 de mayo de 2021.

Rodríguez Salazar, Tania y Rodríguez Morales, Zeyda (2020), "Intimidad y relaciones de pareja durante la pandemia de la COVID-19 en Guadalajara”, Espiral Estudios sobre Estado y Sociedad, vol. 28 (78-79), Guadalajara, Universidad de Guadalajara, OJS/PKP, doi: 10.32870/ eees.v28i78-79.7206

Sarmiento, Sergio (2020), "Contagio moral", Reforma, 17 de marzo, Ciudad de México, Grupo Reforma, Opinión, <https:// bit.ly/2QJQtle>, 20 de mayo de 2021.

Schmidt, Volker (2020), Eight theories of societalization: Toward a theoretically sustainable concept of society, European Journal of Social Theory, 23(3), pp.411430, doi: 10.1177/1368431019850069

Silva-Herzog Márquez, Jesús (2020), "Vulnerables", Reforma, 16 de marzo, Ciudad de México, Grupo Reforma, Opinión, <https://bit.ly/2REqH2b>, 20 de mayo de 2021.

Smith, Philip (2005), Why War? The Cultural Logic of Iraq, the Gulf War, and Suez, Chicago, University of Chicago Press.

Sonnevend, Julia (2020), "A virus as an icon: the 2020 pandemic in images", American Journal of Cultural Sociology, 8, pp. 451-461, Springer, doi: 10.1057/s41290020-00118-7

Suárez-Vélez, Jorge (2020), "Líder o charlatán”, Reforma, 19 de marzo, Ciudad de México, Grupo Reforma, Opinión, <https://bit.ly/3hJpb9J>, 20 de mayo de 2021.

Taussig, Michael (2020), "Would a Shaman Help?", Critical Inquiry, 30 de marzo, Critical Inquiry, In the moment, <https:// critinq.wordpress.com/2020/03/>, 28 de diciembre de 2020 
Vicari, Stefania y Murru, Maria Francesca (2020), "One Platform, a Thousand Worlds: On Twitter Irony in the Early Response to the COVID-19 Pandemic in Italy", Social Media + Society, 1 (4), SAGE, doi: 10.1177/2056305120948

Villegas, Celso (2020), "Performing rituals of affliction: how a Governor's Press conferences provided mediatized sanctuary in Ohio", American Journal of Cultural Sociology, 8, pp. 352-383, doi:10.1057/s41290-020-00116-9

Wieviorka, Michel (2020), "Las ideas sencillas y nuestro futuro", La Vanguardia, 16 de mayo, La Vanguardia Ediciones, Opinión, <https://bit.ly/3foNZRw>, 28 de diciembre de 2020.

Žižek, Slavoj (2020), "El coronavirus es un golpe al capitalismo a lo 'Kill Bill' que podría reinventar el comunismo", RT, 27 de febrero, RT News, Op-ed, <https://bit.ly/3uUAOtd>, 26 de diciembre de 2020.

Recibido: 16 de enero de 2021. Reenviado: 4 de febrero de 2021. Aceptado: 26 de marzo de 2021.

\section{Nelson Arteaga Botello}

Doctor en Sociología por la Universidad de Alicante, España. Actualmente es profesor-investigador de la Facultad Latinoamericana de Ciencias Sociales (México) y Faculty Fellow en el Center for Cultural Sociology de la Universidad de Yale. Es miembro del Sistema Nacional de Investigadores, nivel III. Sus líneas de investigación son sociología cultural, violencia y vigilancia. Entre sus últimas publicaciones destacan: "The Populist Transition and the Civil Sphere in Mexico", en J.C. Alexander, G. Sciortino y P. Kivisto (eds.), Populism in the Civil Sphere, Cambridge, Polity (2020); "Solidary Cuisine: Las Patronas Facing the Central American Migratory Flow", en C. Tognato, N. Jaworsky y J.C. Alexander (eds.), The Courage for Civil Repair. Narrating the Righteous in International Migration, Cambridge, Palgrave-Macmillan (2020); "Strong program cultural sociology and Latin America", American Journal of Cultural Sociology (con Carlo Tognato) (2020); y Sociología y Ciencia Ficción: Philip K. Dick más allá de Orwell y Foucault, Flacso-México (2020). 
